\title{
Analysis on the Leadership Cultivation of Cadets in the New Era
}

\author{
Tao $\mathrm{Hu}^{1}$, Haiyu Zhang ${ }^{1, *}$, and Jun Gong ${ }^{1}$ \\ ${ }^{1}$ Department of Management Engineering and Equipment Economics, Naval University of Engineering, Wuhan 430033, \\ China \\ *Corresponding author.Email: haiyu98@qq.com
}

\begin{abstract}
In the new era, the leadership cultivation of cadets faces such problems as unclear objective, rigid model, poorly structured evaluation mechanism, and unfavorable atmosphere. This paper introduces the systematic measures for leadership cultivation in optimizing the top-level design of leadership cultivation, developing innovative leadership training models and methods, constructing the evaluation mechanism for leadership cultivation, and fostering the cultural and educational environment for leadership. These measures will help further enhance the quality and efficiency of cadet training and effectively guide the training of military talents competent to fight and win any war in the new era.
\end{abstract} Keywords: leadership, teaching skills workshop, case teaching

\section{INTRODUCTION}

Facing the profound changes of national security environment and the needs of a powerful country with strong army in the era, Xi Jinping's thoughts and ideas on building a strong army were distinctively highlighted at the $19^{\text {th }}$ National Congress of the Communist Party of China. It was emphasized that the people's army would be built into the world's first-class army in an all-round way by the middle of the $21^{\text {st }}$ century, while a clear timetable and indicator system had been also put forward for this purpose. Building a first-class army entails the support of first-class military academies. A first-class military academy centers on training first-class military talents. Leadership is a core quality of first-class military talents. For this reason, training the military talents "for battlefield, army, and the future" has an essential demand for the leadership cultivation of cadets in the new era. The leadership cultivation of cadets can not only effectively guarantee that "everything is oriented by combat effectiveness and focuses on the competence to fight and win any war", but also provide a radical way to nurture the modern military personnel and build first-class military academies.

\section{EXISTING PROBLEMS IN THE LEADERSHIP CULTIVATION OF CADETS}

\subsection{The Objective Is Unclear}

The military academies in developed countries have different but clearly defined training objectives. For instance, the US Military Academy at West Point keeps the mission "to prepare the leaders with professional excellence, physical strength and high morality for the nation"; the US Navy Academy aims to "train the navy leaders for service to the nation"; the UK Royal Military Academy Sandhurst focuses on training cadets with the idea and professional quality for "serving to be a leader"; the France Special Military School of Saint Cyr, praised as "the great academy for the training of military leadership", has put first the command capability and leadership of cadets. However, China still keeps the objective to "integrate command and skill", whether ideologically or practically, in the military training. We may therefore ignore the needs of future development and overlook the cultivation of cadets' development potentials while paying much attention to the current conflicts.

In recent years, the academies have attached greater and greater importance to the leadership cultivation of cadets. However, there is not yet a clear, unified, scientific or systematic understanding of such questions as "what the leadership of cadets is, what elements are included in leadership, and what type of leadership cadets need to fulfill basic tasks and meet the army's requirements". These issues have not been scientifically or systematically analyzed and explored. The academies may have made lots of ideas and efforts in the talent training, demonstrating their intention to cultivate the leadership of cadets. Nevertheless, they lack the unified objective, scientific indicator system and criteria, and focused plans and measures, and have no dedicated mechanism or specific institution for leadership cultivation. In the practical teaching, these academies have to rely more on the personal ideology, experience and professional quality of teachers and cadres for spontaneous cultivation, and do not implement the top-level design, objective-oriented guidance, and policy-based guarantee. Hence, there are shortcomings in their leadership cultivation of cadets, causing some prominent "conflicts". 


\subsection{The Leadership Training Model Needs to Be Urgently Changed}

At present, the academies often adopt the model of "theoretical learning + field practice" in leadership training. With regard to teaching, they offer leadership and management courses to teach leadership as a kind of disciplinary knowledge in classrooms. As for management, posts and platforms are set up to encourage the participation of cadets in management, so that cadets can accumulate the experience in leading. This model can help improve the leadership of cadets to some extent, but still have the following problems. Firstly, it is not highly practical. Some teaching methods such as case study and group discussion may be employed to teach theoretical courses, but it is very difficult for cadets to experience how to behave as a leader, which leads to unreliable practice and insufficient reflection and further alienates "knowledge" from "action". Secondly, it is not focused. Cadets are required to study the knowledge comprehensively in courses and have comprehensive practice in work. Hence, cadets experience leadership in an "extensive but shallow" way, which is not well focused. Additionally, leadership improvement is closely related to cadets' values, attitude toward work, habits, and psychological factors apart from the traditional "theory + practice" integration. Consequently, it is very difficult to rely on classroom teaching and utilize mixed teaching methods comprehensively to help cadets explore their potentials, change their attitudes and habits, and reflect on their behaviors.

\subsection{The evaluation Mechanism Is Less Systematic}

The existing evaluation system for cadets does not include the leadership evaluation and feedback. It follows some indistinct criteria, has a long evaluation cycle, and lacks frequent and leadership evaluation. To simulate the cadre training at posts and the participation in club activities, it is necessary to further optimize and improve the effectiveness of evaluation indicators, the diversity of evaluation methods, the inclusiveness of evaluation objects, the guiding effect of evaluation conclusions, and the interval of evaluation cycle.

\subsection{The Training Atmosphere Is Not Strong}

Leadership is gradually nurtured in the four-year education, teaching, training and activities provided by the academies. It is inevitably affected by the cultural environment. In the training of cadets, leadership has however not received sufficient attention, and not been correctly understood, collectively taught or widely recognized. Hence, the academies have no good environment and atmosphere for leadership cultivation[1].

\section{MEASURES FOR THE LEADERSHIP CULTIVATION OF CADETS IN THE NEW ERA}

\author{
3.1. Optimizing the Top-Level Design of \\ Leadership Cultivation
}

\subsubsection{Put leadership cultivation at the center of education}

Firstly, we can borrow the ideas of cultivation from some famous academies such as the US Military Academy at West Point and the US Navy Academy, and take the idea of "educating the outstanding leaders serving the national defense for the army" as the objective and mission of military academies in the talent training. Moreover, leadership cultivation should be propagandized, spread and promoted to make its role and significance recognized both ideologically and behaviorally[2];

Secondly, the leadership cultivation objective system is further optimized and specified considering the actual condition of each military academy. The objective system is hierarchically organized for extensive implementation, so that every unit and individual involved in the leadership cultivation process can understand "what the leadership of cadets is and what factors and indicators are involved in the leadership";

Thirdly, leadership cultivation should be put first in the development of talent training program, the creation of curriculum and the teaching process to solidify the basis for leadership cultivation in the talent training system.

\subsubsection{Rebuild the path of leadership cultivation}

The leadership of cadets should be cultivated and shaped by integrating all kinds of teaching measures and methods and following the objective system in a procedural, hierarchical, and all-directional way. Analyzing the current status of leadership among cadets and the existing path of leadership cultivation can help more clearly and accurately assess, understand and identify the current leadership of cadets and the existing measures and activities for leadership cultivation. On this basis, the path of leadership cultivation can be rebuilt.

Firstly, the four-year training cycle is taken as the basis for the academies to scientifically set its periodic objectives and evaluation criteria for leadership cultivation[3].

Secondly, it is necessary to identify the effectiveness of the path and its existing problems, and then develop more specific measures and plans for optimizing the existing path of leadership cultivation. Based on the conclusion of the analysis on the current status of leadership among cadets, some specific ways and methods are added and improved for leadership cultivation to address the "limitations" in the objectives. 
Thirdly, leadership cultivation modules are included in the development of talent training program, the creation of curriculum and the entire teaching process in every school year. The training system for leadership cultivation should be constructed in three dimensions, that is, time, objective and path, while "shop drawings" are employed to present the detailed path, contents and their logical relations in the leadership cultivation.

\subsection{Developing the Innovative Leadership Training Models and Methods}

\subsubsection{Develop the coaching-based leadership training models and methods}

Based on the requirements of practical teaching in the new system and mechanism, the basic ideas and methods of coaching are studied to develop the innovative leadership teaching and implementation process by virtue of the leadership training platform. The tutoring and experiential training are taken as the main models to help cadets embrace the role as a leader, experience the leading situation, and behave like a leader. In this way, cadets can gradually reinforce their command decision-making capability in practice and eliminate their shortcomings in the leadership cultivation through self-reflection. Therefore, they can change own leadership behaviors and enhance own management quality.

\subsubsection{Rely on the training platform for practical and exploratory leadership teaching}

Firstly, each academy can establish a leadership training laboratory and leadership activity club considering its own situation for the coaching-based practical and exploratory leadership training. The training is mainly experiential and performed "in + after" class. The "in-class" training is "coaching-based and result-oriented". It is a coaching-based and restructured training process directed by teachers. For the "after-class" training, assistant coaches are elected and trained in the way of "being directed by cadets under the guidance of teachers". Cadets are organized freely, from different grades, on and off campus, in and after class to take part in various scenario simulation and training activities. In this way, the contents of the "in-class" training are expanded and extended. Secondly, the existing training model of management courses is innovatively optimized to gradually expand the coaching and leadership training into the basic courses for leadership management.

\subsection{Constructing the Leadership Cultivation Evaluation Mechanism}

\subsubsection{Establish the whole-process evaluation mechanism}

Leadership is evaluated in the entire training process. A reasonable indicator system is created to quantify leadership. Feedbacks are given to help cadets understand own problems and make any improvement in a timely manner. A training academy can also arrange the teaching for cadets and develop the special training plans based on the leadership evaluation results[4].

\subsubsection{Establish the three-dimensional evaluation system and feedback mechanism}

Firstly, a three-dimensional leadership evaluation system is scientifically established. The criteria are specified hierarchically based on the leadership evaluation indicator system to lay a foundation for the comprehensive and accurate evaluation of leadership. [5] Secondly, a variety of evaluation subjects are included. The evaluation subjects include teachers, cadres, and cadets. Their weights are rationally determined to ensure the objective and reliable evaluation. Thirdly, great importance is attached to the use and feedback of evaluation results. The evaluation aims to find out the shortcomings in the leadership, so as to prepare the tailored improvement plan and eliminate the shortcomings in a focused manner. In this way, it can help give play to the personality traits of cadets to the maximum and improve their leadership on the whole.

\subsubsection{Establish the incentive mechanism}

The quantitative indicators for the leadership evaluation of cadets are scientifically integrated with the comprehensive quality evaluation at the time of graduation, and also taken as the important basis for electing the outstanding students and cadets to whom priority is given in the application for graduate education and the grant of professional title and level.

\subsection{Nurturing the Cultural and Educational Environment for Leadership}

The cultural environment for leadership provides the soil for leadership cultivation. Cadets can gradually develop leadership in the four-year education, teaching, training and activities provided by the academies, which depends on the cultural environment on campus[6].

Firstly, a positive ideological and political environment should be solidified. A diversity of well-designed educational activities are organized to "foster the leadership" physically and psychologically, cultivate the 
leadership unconsciously, and inspire cadets with dedication to national defense, sense of responsibility and bravery in leading.

Secondly, a favorable cultural atmosphere is created on campus. Campus culture is an important aspect of educational environment in a military academy. Leadership grows in the campus culture. The cultural publicity for leadership is extensively implemented by utilizing the political works website, glass-fronted billboard and blackboard newspaper, WeChat official account, broadcasting service, and school newspaper on campus. A variety of activities are carried out with leadership as the theme. Cadets are encouraged to voluntarily undertake and take part in these activities, so that they can think like a leader. In this way, cadets will develop the enthusiasm for leading activities as well as the quality of leader;

Thirdly, a barracks environment is created to educate reliable and courageous leaders who are brave to lead and competent to coordinate. More military combat simulations and drills should be carried out in the training to test cadets in severe circumstances for ideology, style, psychology and physique, and polish their quality in bravery, firmness, calmness, determination and tenacity. These efforts are made to improve the effect of leadership cultivation. Some events are organized such as military skill competition and military forum to encourage the military spirit and cultural atmosphere, reinforce the combat atmosphere, and foster the quality of leadership. The hierarchical management mechanism is strictly implemented to classify cadets into four levels based on which year they are enrolled. The cadets in each level undertake different responsibilities for leading, and some measures are developed to realize their early promotion or demotion. Therefore, cadets can practice their leading skills in the "interactive" process of leading and being led.

Fourthly, an advanced and efficient information environment is constructed to strengthen the creation of digital leadership information and resources and create the leadership cultivation management system, evaluation system, feedback and consulting system.

\section{CONCLUSION}

The decisive factor in the future battlefield is people, whose leadership is the core quality. How to train future officers with a high level of leadership for the army requires strengthening strategic planning, innovating ideas and concepts, and taking pragmatic measures. In order to continuously promote the training of talents in our military, the ideas and countermeasures for cultivating the leadership of Cadets proposed in this article need to be tested and explored in practice .

\section{REFERENCES}

[1] B. Jiang and N, Xiao, "Analysis on the leadership cultivation of cadets in Chinese military academies", Education Forum, Vol. 28, pp. 52-53, 2016. (In Chinese)

[2] H. Y. Yu and X. G. Wang, "Experience in the leadership cultivation of major foreign navy academies" , Theory Research, Vol. 20, pp. 120-121, 2015. (In Chinese)

[3] X. Wang, "Exploration on the practical cultivation of leadership for cadets in other countries" , AsiaPacific Education, Vol. 11, pp. 63-64, 2015. (In Chinese)

[4] B. Liu, S. L. Huang, T. G. Yu and L. Z. Zheng, "Research on the design of leadership evaluation indicators and system for cadets". Education Forum, Vol. 20, pp. 226-227, 2019. (In Chinese)

[5] E. Yang, "Reflection on improving the leadership of cadets with fuzzy comprehensive evaluation", Peak Data Science, Vol. 10, pp. 48-49, 2017. (In Chinese)

[6] Z. Yang, "Leadership is charisma: Decoding the leadership of the West Point", Science and Technology of China, Vol. 12, pp. 95-98, 2016. (In Chinese) 